\title{
BMJ Open Top-cited articles in medical professionalism: a bibliometric analysis versus altmetric scores
}

\author{
Samy A Azer, ${ }^{1}$ Sarah Azer ${ }^{2}$
}

To cite: Azer SA, Azer S. Top-cited articles in medical professionalism: a bibliometric analysis versus altmetric scores. BMJ Open 2019;9:e029433. doi:10.1136/ bmjopen-2019-029433

- Prepublication history and additional material for this paper are available online. To view please visit the journal (http:// dx.doi.org/10.1136/bmjopen2019-029433).

Received 25 January 2019 Revised 26 April 2019 Accepted 1 July 2019

Check for updates

(C) Author(s) (or their employer(s)) 2019. Re-use permitted under CC BY-NC. No commercial re-use. See rights and permissions. Published by BMJ.

${ }^{1}$ Professor of Medical Education, Department of Medical Education, King Saud University, College of Medicine, Riyadh,

Saudi Arabia

${ }^{2}$ Senior Robotic Fellow, Department of Urology, Southmead Hospital, Bristol, United Kingdom

Correspondence to Professor Samy A Azer; azer2000@optusnet.com.au, mcqsmcqs@hotmail.com

\begin{abstract}
Introduction Citation counts of articles have been used to measure scientific outcomes and assess suitability for grant applications. However, citation counts are not without limitations. With the rise of social media, altmetric scores may provide an alternative assessment tool. Objectives The aims of the study were to assess the characteristics of highly cited articles in medical professionalism and their altmetric scores.
\end{abstract}

Methods The Web of Science was searched for top-cited articles in medical professionalism, and the characteristics of each article were identified. The altmetric database was searched to identify report for each identified article. A model to assess the relationship between the number of citations and each of the key characteristics as well as altmetric scores was developed.

Results No correlations were found between the number of citations and number of years since publication $(p=0.192)$, number of institutes $(p=0.081)$, number of authors $(p=0.270)$, females in authorship $(p=0.150)$ or number of grants $(p=0.384)$. The altmetric scores varied from 0 to 155 , total=806, median=5.0, $(I Q R=20)$. Twitter $(54 \%)$ and Mendeley (62\%) were the most popular altmetric resources. No correlation was found between the number of citations and the altmetric scores $(p=0.661)$. However, a correlation was found for articles published in 2007 and after $(n=17, p=0.023)$. To further assess these variables, a model was developed using multivariate analysis; did not show significant differences across subgroups. The topics covered were learning and teaching professionalism, curriculum issues, professional and unprofessional behaviour.

Conclusions Altmetric scores of articles were significantly correlated with citations counts for articles published in 2007 and after. Highly cited articles were produced mainly by the USA, Canada and the UK. The study reflects the emerging role of social media in research dissemination. Future studies should investigate the specific features of highly cited articles and factors reinforcing distribution of research data among scholars and non-scholars.

\section{INTRODUCTION}

Citation counts have been used by universities and funding bodies to measure scientific outcomes, make decisions about professional promotion and assess suitability for grant applications. ${ }^{12}$ In this context, it was claimed that the higher number of citations received,

\section{Strengths and limitations of this study}

Four searches were conducted in the web of Science database and the altmetric tracks.

- The analysis explored a range of bibliometric parameters.

- The study was limited to top-cited articles in the English language.

the higher quality of work and the more likely that other researchers cite the work. ${ }^{3}$ While these claims may not necessarily be true, there is a substantial body of evidence that the number of citations correlates with other research achievements including research awards, honours, nomination for Nobel laureateship, ${ }^{3} 4$ prestigious research positions ${ }^{5}$ and academic ranking. ${ }^{6}$ However, there are factors other than scientific quality that may affect the decision to cite. ${ }^{8}$ For example, there is evidence that early interest in a research publication reflected by online access within a week of publication predicts citations up to 15 years later. ${ }^{9}$ Also, scientific citations favour positive results and authors tend to cite primarily works by authors with whom they know and personally acquainted. ${ }^{10} 11$

With these limitations in mind, there is a continuous search for alternatives or metres that can complement the citation counts. Currently, there is a rising interest in the altmetric scores. Contrary to traditional citation-based analysis, the altmetrics reflect the widespread attention to published scientific articles and the rise of social media for dissemination and discussion of scientific information. Therefore, it is possible to quantify discussion of an article on blogs, news media or other social media platforms. ${ }^{12}$

Considering these two tools, it was decided to assess highly cited articles on medical professionalism. ${ }^{13}{ }^{14}$ The top-cited articles were selected because an earlier study revealed a number of attributes of articles on medical professionalism. ${ }^{14}$ The use of the 
altmetric scores in this study in particular is thought to be useful since articles on professionalism are usually shared on social media.

Therefore, the present study aims at the following: first, identify the most-cited articles in medical professionalism and evaluate their characteristics, and study any correlations between the number of citations and each of their biliometric characteristics. Second, assess the impact of such articles on social media by calculating the altmetric scores and conducting an exploratory analysis examining the altmetric findings compared with citation analysis. The conduction of multivariate analysis model may provide additional insight into such evaluation. The findings from this study may enable researchers to identify common features of articles behind the progress of medical professionalism and key topics discussed over the last two to three decades. The study may provide more insight into any relationships between citation analysis and the altmetric scores. The identified list of publications may be useful to medical educators and those teaching medical professionalism or doing masters or research in these areas.

\section{METHODS}

\section{Study design}

To achieve the objectives of this study, it was decided to search the Web of Science database of Clarivate Analytics for highly cited articles and track the citation records of publications identified. Although Scopus and Google Scholar databases also provide citation tracking, it was decided to limit the search to the Web of Science. This is because the Web of Science is regularly updated and its 2016-Journal Citation Reports reported over 59 million citations in its Science Edition and 7 million from its Social Science Edition. In the area of medical education, medical ethics and bioethics, general medicine and surgery, the Web of Science has included 16, 49, 457 and 180 peer-reviewed journals, respectively. Google Scholar was not included in the search because it is difficult to search, and it is not possible to identify the number of citations for each year across the last two to three decades, and the citations in Google Scholar usually include textbooks, monographs, conference proceedings, as well as non-peer-reviewed work. The Scopus database was not included in our search because its records only go back to 1966 .

To achieve the first aim, we planned to identify the highly cited articles in medical professionalism and their characteristics using three mechanisms: (1) searching the Web of Science using keywords, (2) searching medical education, ethics, general medicine and surgery journals in the Web of Science, (3) searching the webpage of journals and (4) searching for related resources mentioned in the list of references of articles identified. For the second aim, the altmetric bookmarklet application was used to obtain the altmetric scores and construct exploratory analysis examining the role of social media and the different resources contributing to altmetrics. At the end, we compared these findings with those obtained from the citation analysis. ${ }^{15-17}$ A description of the steps used in the search is discussed below.

\section{Searching the web of science database using keywords}

Searching the Web of Science database was carried out in the 5 April 2017 by two researchers (SAA is a professor of medical education with a 20-year experience in research in the field of medical education and professionalism, and SA a surgical registrar and researcher). The search words used were the following: 'Medical professionalism', 'Patient safety', 'Professional behavior', 'Unprofessional behavior', 'Role modeling', 'Accountability', 'Faculty training in professionalism', 'Altruism', 'Physician code', 'Physician charter', 'Medical ethics', 'Integrity', 'Consent', 'Defining medical professionalism', 'Empathy', 'Compassionate doctor', 'Professional conduct', 'Collaborative doctor', 'Self-assessment', 'Professional development', 'Resilient doctor', 'Social justice', 'Patient autonomy', 'Patient Welfare', 'Professional responsibility', 'Managing conflict', Patient confidentiality', 'Quality of care', 'Social contract', 'Team work and professionalism', 'Personal development', 'Public professionalism', 'Interpersonal professionalism' and 'Intrapersonal professionalism'. These keywords were identified from the terminology and themes used in defining medical professionalism in six resources including. ${ }^{18-23}$ We also looked at conference proceedings in the field and websites of organisations and agencies responsible for accreditation of medical education worldwide including: The World Federation for Medical Education, the UK's General Medical Council, the Association of American Medical Colleges, the Australian Medical Council, the Liaison Committee on Medical Education, and the Quality Assurance of Basic Medical Education, and documents such as: Tomorrow's doctors, 2003; The New Doctor, 2004; and General Medical Practice, 2001.

For each search word, the results were arranged using a link on the Web of Science database system 'sort-by''Time Cited- highest to lowest'. The results showed the articles organised in a descending order with the articles most frequently cited on the top. The findings from each search word were then arranged on one Excel sheet in a descending order based on the number of citations. The results identified by each evaluator were discussed and duplicate articles were excluded.

\section{Searching journals in the Web of Science}

The second search involved searching all journals in the field of medical education, ethics, general medicine and surgery included in the Web of Science database. These journals are known to publish articles on medical professionalism. They were selected on the basis of the outcomes of the Web of Science search and the references cited by the articles identified. The aims of this second search were to maximise the yield of the search and detect any articles that were possibly missed during the first search. 
This search was conducted under the same conditions of the first search, by the two researchers, on the same day, and by using the same keywords used in the first search. The journals in medical education that were searched included Academic Medicine, Medical Education, Medical Teacher, BMC Medical Education, Advances in Health Sciences Education Theory, and Practices, Teaching and Learning in Medicine and the Journal of Continuing Education in the Health Professions. The journals searched in general medicine and surgery were the New England Journal of Medicine, the Lancet, the British Medical Journal, the Journal of the American Medical Association, Journal of General Internal Medicine, Annals of Internal Medicine, Archives of Internal Medicine, Canadian Medical Association Journal, PLOS Medicine, Annals of Surgery, Archives of Surgery, British Journal of Surgery, Perspectives in Biology and Medicine, Mayo Clinic Proceedings and the Australian Medical Journal. The journals in bioethics that were searched included the American Journal of Bioethics, Journal of Medical Ethics and BMC Medical Ethics. The findings from journals were then arranged on one Excel sheet in a descending order based on the number of citations. The results identified by each evaluator were discussed and duplicate articles were excluded.

\section{Searching the webpage of journals}

To maximise the yield of our search and to ensure that no paper was missed through searching the Web of Science, we conducted a third search using the webpage of the journals mentioned above. We examined the titles of articles listed in each issue of these journals during 2011 and prior years. This search was particularly important as for example, Teaching and Learning in Medicine first appeared in Web of Science in 1996 but the journal was published since 1989. Therefore, any relevant articles from this journal or others prior to 1996 would be included.

\section{Inclusion and exclusion criteria}

The inclusion criteria were: (1) papers focusing on medical professionalism in the English language and (2) articles, reviews, research papers, reports, editorials on any aspect related to medical professionalism in the English language. The exclusion criteria were: (1) articles on medical professionalism in languages other than English, and (2) articles that focused on education/curriculum or clinical practices and medical professionalism was not the main focus. Articles with identical absolute number of citations were ranked on the basis of the average citation per year (the number of citations obtained divided by the number of years since published) ${ }^{24} \mathrm{~A}$ copy of all papers included in the list was obtained and read by the evaluators.

It is interesting to note that none of the articles excluded on the basis of language were qualified for inclusion in the list because they had less citation numbers than those of the article marked number 50 in the list.

\section{Assessing the articles}

For each of the identified articles (online supplementary appendix 1), a full text was obtained and a copy was given to each researcher. The following information was collected: (1) the authors' names and their affiliations, and the number of females contributing to authorship (2) the number of institutes involved and the city and country of the origin of the publication, (3) the total number of citations obtained up to the day of searching the database, and the number of yearly citations since publication, (4) the year of publication and the calculated number of years since publication and (5) grants/ funding bodies stated in the publication and (6) the 2016-JIF of the journal that published the work.

We also aimed at grouping the identified top-cited articles into categories. We have not used the categories provided by the Web of Science 'study type' because we noted that the Web of Science system does not differentiate between 'original research' or 'articles' and classified both as 'articles'. For consistency and the purpose of this study, we grouped the articles into four categoriesarticle, review, editorial material and research. A definition of each category is given in the glossary. Using these definitions, two researchers independently allocated each article under a category. For articles that were difficult to classify or not fitting into the same category, a meeting was held to discuss these articles and a final decision was made.

The topics covered in identified articles were created by each researcher independently by generating key words reflecting the main idea covered in an article and using these words to phrase a short statement that could help in grouping more than one article under one topic. The topics were then discussed in a meeting to harmonise the grouping into a logical, simple and practical approach. Articles covering more than one topic were classified on the basis of the aim of the study, the title and the main outcomes.

\section{Identification of author's gender}

Regarding the data collected for each article, it is important to mention here that the identification of the gender of each author was a challenging task particularly when a journal uses abbreviations of the first and second name rather than the full name, which was the case in three articles. The approach used in order to identify the females in the top-cited articles included (1) searching the Google database to find the university website, personal website of the author, LinkedIn webpage and ResearchGate account. This approach was particularly useful for authors who could have moved to other universities, (2) searching the university websites not only provided the full names but also provided identification photos of these authors, and in many times a list of their publication records, as well as areas of research/ teaching interests (3) Searching the Google Scholar database to identify their accounts, where we can find other publications under their names, the full name or an 
identification photo showing them. Usually, authors of highly cited articles have other publications related to the same topic, or work with the same coauthors, which could also help in identifying them and tracing them and (4) In two difficult cases we emailed the corresponding author of these articles for help.

\section{Altmetric system}

The altmetric system comprises, but not limited to, policy documents, news, blogs, tweeters, online reference managers (eg, Mendeley, CitULike), postpublication peer reviews (eg, Publons), Social media platforms (eg, Facebook, Google+, Pinterest), citations on Wikipedia, sites running Stack Exchanges (Q\&A) and reviews on Faculty 1000 (F1000) and YouTube. Therefore, altmetric scores may reflect interest of the public as well as clinicians and researchers in a publication and the scores may provide information about the geographical and demographic details of those involved in such online/social media discussions. ${ }^{25}$

The altmetric programme processes raw data collected from the above-mentioned resources and the data are weighted according to a system created by altmetrics to reflect the relative contribution of each source to the total altmetric score. News, Blogs, Wikipedia and policy documents have a relatively higher weighting values. ${ }^{26}$ While Mendeley and CiteULike are shown in the report, they do not contribute to the total score.

\section{Searching the altmetric system}

The search of the altmetric system was conducted on the same day (5 April 2017). The scores were identified using the Altmetric bookmarklet provided by the company. ${ }^{27}$ In summary, the articles were searched on PubMed database (the PMID or DOI are essential for triggering the altmetric bookmarklet to function). By clicking on the LinkOut link, we identified the publisher webpage hosting the original article and by clicking the altmetric bookmarklet application, we can check the attention records for the article. The altmetric attention score and donut help in identifying the relative quantity and the type of attention received by a published article. The meaning of the colours included in altmetric donut is explained in this link. ${ }^{28}$

\section{Statistical analysis}

All analyses were conducted using SPSS Software (IBM SPSS Statistics Premium V.22.0 for Mac OS-SPSS) and the results were reported at total, mean, median, IQR and percentage. Pearson's correlation coefficient (r) was calculated to determine if the high citation numbers obtained were related to parameters characteristic of articles. Because of the observed differences in the citations of the top articles in the list compared with those in the bottom of the list, and the variability in the altmetric scores, it was decided to conduct a multivariate analysis model comprising the effect of number of authors and other parameters. The inter-rater agreement between evaluators was calculated using the Fleiss kappa scale. ${ }^{29}$

\section{Patient and public involvement}

Patients and the public were not involved in this study.

\section{RESULTS}

\section{Top-cited papers identified}

Online supplementary appendix 1 summarises the 50 most-cited articles in medical professionalism identified by searching the Web of Science database, ${ }^{30-79}$ out of a total of 3500 articles identified on professionalism. The articles are listed in a descending order from 1 to 50 with the highest absolute citation number is ranked 1 and the article with the lowest citation ranked 50 as per the day of the search. Articles with the same number of citations were ranked on the basis of average citation per year (eg, the articles ranked 34 and 35 had the same citation number 97 , they were allocated to a ranking order based on the calculated citation per year, 13.86 and 7.46, respectively). Other articles that had the same citation number and were ranked on the basis of their calculated citation per year were articles ranked 36 and 37; 43 and 44; as well as 46 and 47.

Table 1 summarises the year of publication and article category. The articles were published over 17 years (from 1994 to 2011). During the period from 1994 to 1999, only seven articles $(14 \%)$ were published. However, the number increased significantly from 2000 to 2005 making a total of $24(48 \%)$ articles. The number in the years from 2006 to 2011 dropped to $19(38 \%)$. No correlation was found between the citation counts of these papers and

\begin{tabular}{|c|c|c|c|c|c|c|c|}
\hline \multirow{2}{*}{$\begin{array}{l}\text { Article } \\
\text { category }\end{array}$} & \multicolumn{7}{|c|}{ Year of publication: no of articles (reference) } \\
\hline & 1994-1996 & 1997-1999 & 2000-2002 & 2003-2005 & 2006-2008 & 2009-2011 & Total (\%) \\
\hline Article & & $2^{5974}$ & $4^{35466067}$ & $8^{4047495153616476}$ & $3^{336568}$ & $2^{6975}$ & 19 (38) \\
\hline Review & $1^{78}$ & $2^{3250}$ & $2^{3036}$ & $4^{55} 566270$ & & $2^{3852}$ & $11(22)$ \\
\hline $\begin{array}{l}\text { Editorial } \\
\text { material }\end{array}$ & & $1^{44}$ & $1^{57}$ & $1^{31}$ & $1^{58}$ & & $4(08)$ \\
\hline Research & & $1^{42}$ & & $4^{34} 376673$ & $5^{4345485471}$ & $6^{394163727779}$ & 16 (32) \\
\hline Total (\%) & $1(2)$ & $6(12)$ & 7 (14) & 17 (34) & $9(18)$ & $10(20)$ & 50 (100) \\
\hline
\end{tabular}


the number of years since publication (Pearson correlation $(\mathrm{r})=0.188, \mathrm{p}=0.192)$.

The distribution of the medical professionalism topics covered in these articles is summarised in table 2. The inter-rater agreement between assessors was in the range $0.758-0.846$.

The articles were published in the following journals: Academic Medicine ( $\mathrm{n}=19,38 \%)$, the Journal of the American Medical Association ( $\mathrm{n}=9,18 \%)$, Journal of General Internal Medicine $(\mathrm{n}=4,8 \%)$, Annals of Internal Medicine $(\mathrm{n}=4,8 \%)$, the New England Journal of Medicine $(\mathrm{n}=3,6 \%)$ and Medical Education (n=3, 6\%). It is interesting to note that $24(48 \%)$ articles were published in eight general medicine journal and the remaining were published in four medical education journals and one journal specialised in bioethics. Most journals have high journal impact factors and are on the top of their field (table 3). This finding reflects the significance of medical professionalism in undergraduate and postgraduate training. The first author of the top-cited articles was from the USA ( $\mathrm{n}=37,74 \%)$, Canada $(\mathrm{n}=8,16 \%)$, the UK $(\mathrm{n}=2,4 \%)$, Germany $(\mathrm{n}=1,2 \%)$, Israel $(n=1,2 \%)$ and New Zealand $(n=1,2 \%)$.

Table 4 summarises the 26 authors who have contributed to two or more articles in the list. Of these, five authors were the first authors of two or more papers, 10 were coauthors of two or more papers, and the remaining 11 were the first authors and coauthors of two or more articles. Top authors were Papadakis, $\mathrm{M}(\mathrm{n}=4$; first author of all four papers) and Blank, $\mathrm{L}$ ( $\mathrm{n}=4$; first author of one paper and coauthor of three). Other top authors are shown in table 4.

The leadership of universities and institutes that have contributed to the creation of these publications are shown in online supplementary appendix 1.

\section{Characteristics of the top-cited articles}

These articles were created by 252 authors, median 4, minimum 1, maximum 19, IQR 4 and the females in authorship were 102 , median 2 , minimum 0 , maximum 11, IQR 2. The institutes involved were 168, median 2, minimum 1, maximum 17, IQR 3; the countries involved were 67 , median 1 , minimum 1 , maximum 9 , IQR 0 ; and the grants/funds received were 35 , median 0 , minimum 0 , maximum 8, IQR 1. Significant correlations were found between the number of citations and the 2016JIF (Pearson correlation $(r)=0.318 ; p=0.024$ ), and the number of countries $(r=0.453 ; p=0.001)$. No significant correlations were found between the number of citations and the number of years since publication $(\mathrm{r}=0.188$, $\mathrm{p}=0.192)$, the number of authors $(\mathrm{r}=0.159 ; \mathrm{p}=0.270)$, the number of females in authorship $(\mathrm{r}=0.343 ; \mathrm{p}=0.150)$, the number of institutes involved $(\mathrm{r}=249 ; \mathrm{P}=0.081)$ or the number of grants received $(\mathrm{r}=-0.126 ; \mathrm{p}=0.384)$.

\section{The altmetric scores}

The altmetric scores and reports were found for $70 \%$ of articles. The total scores were 806 , median 5 , minimum 0.0 , maximum 155, IQR 20. No correlation was found between the number of citations and the total altmetric scores $(\mathrm{r}=0.064 ; \mathrm{p}=0.661)$. A significant correlation was found between number of citations and altmetric scores for articles published in 2007 and after $(n=17, r=0.547$, $\mathrm{p}=0.023$ ). No correlation was found for articles published in 2006 or earlier. Only $38 \%$ of the articles had readers on CiteULike (mean 1.6, 95\% CI 0.4 to 2.7, median 0, minimum 0 , maximum 19, IQR 1; while $62 \%$ were read Mendeley (mean 72.7, 95\% CI 45.2 to 100.3 , median 39.5, minimum 0, maximum 499, IQR 120. The coverage of journal articles by Twitter was 54\% (mean 7.8, 95\% CI 2.7 to 13.0 , median 1.5, minimum 0 , maximum 117, IQR 10) followed by blogs $38 \%$ (mean 1.2, 95\% CI 0.6 to 1.8 , median 0 , minimum 0 , maximum 7 , IQR 1 , then policy sources $24 \%$ (mean $0.38,95 \%$ CI 0.15 to 0.61 , median 0.0, minimum 0.0, maximum 3, IQR 0, then Facebook $20 \%$ (mean $0.3,95 \%$ CI 0.07 to 0.61 , median 0 , minimum 0 , maximum 6 , IQR 0 ). The Wikipedia was the lowest resource. No significant correlation was found between the number of citations and altmetric scores $(\mathrm{r}=0.064$; $\mathrm{p}=0.661$ ). The geographical breakdown showed that USA had the highest share, followed by UK. Other countries identified for some articles were Canada, Mexico, Spain, Australia, Spain, Chile, Netherlands, Portugal, Japan, Columbia, Italy, France and Brazil. We looked at journals' webpages of the top-cited articles and those hosting the altmetric metre; we did not find significant correlation between hosting the altmetric metre and recorded altmetric scores.

\section{Multivariate analysis}

Because of the observed differences in the citations of the top articles in the list compared with those in the bottom of the list, and the variability in the altmetric scores, it was decided to conduct a multivariate analysis comprising the effect of number of authors, number of institutes, number of countries, number of females in authorship, number of grants obtained on the citation scores and altmetric scores (table 5).

\section{DISCUSSION}

The aims of this study were to identify the highly cited papers in medical professionalism and compare their characteristics and citation analysis with the altmetric scores. Currently, there is a great interest to examine if there is a relationship between altmetric indicators and citation counts. The question remains can we measure the impact of scientific publications by measuring their social density effects?

The study has identified key topics related to medical professionalism including: learning/teaching professionalism and curriculum issues, professional and unprofessional behaviour/disciplinary actions, defining and measuring medical professionalism, response to conflict, social responses and social environment, empathy and moral development, online social networking and professionalism, quality improvement and evidence-based 


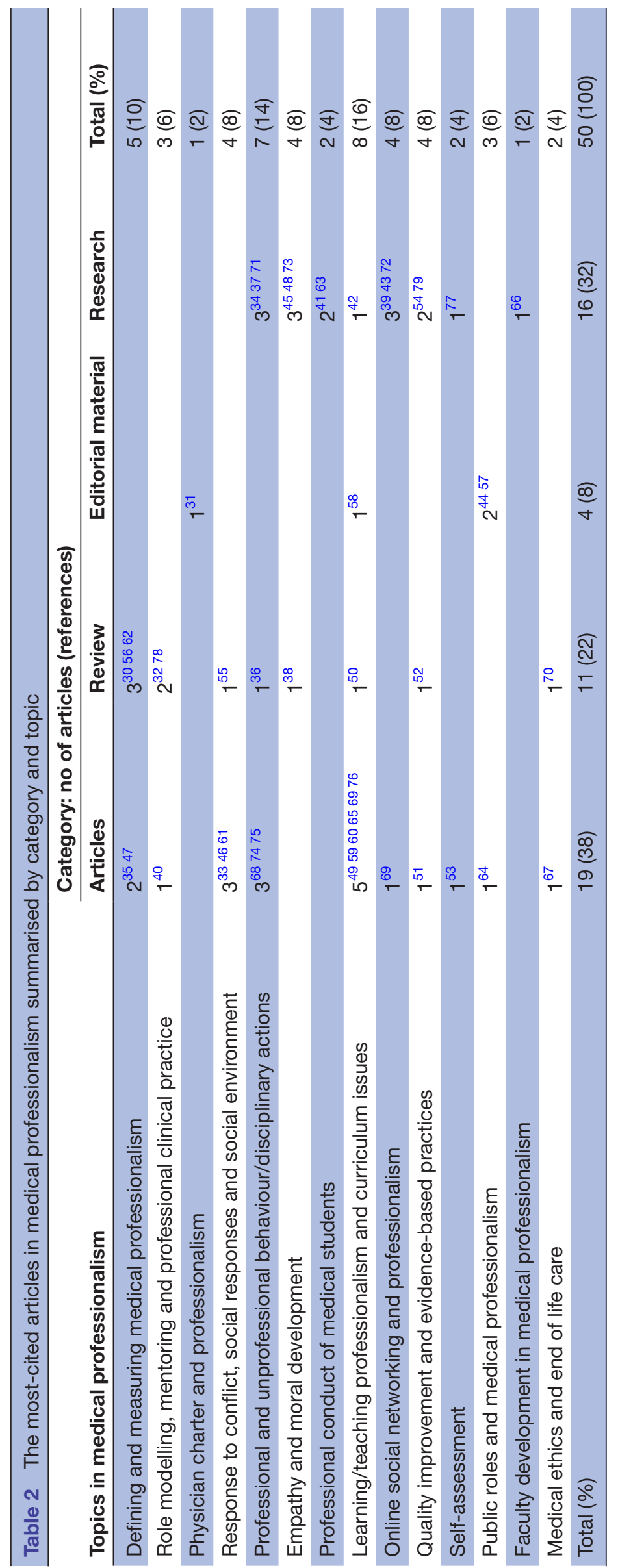

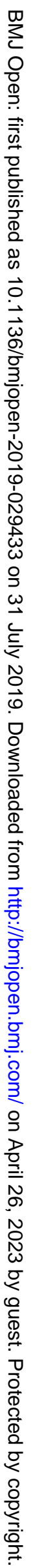


Table 3 The journals that published the top-cited articles in medical professionalism and the journal impact factor

\begin{tabular}{lcc}
\hline Journal & 2016-Journal Impact & \\
\hline Journal of the American Medical Association & 44.405 & No of papers published (references) \\
\hline New England Journal of Medicine & 72.406 & $9^{303233394142646775}$ \\
\hline Academic Medicine & 5.255 & $3^{344457}$ \\
Journal of General Internal Medicine & 3.701 & $19^{35-384045-475052565960636568707477}$ \\
Medical Education & 4.005 & $4^{43486169}$ \\
Health Affairs & 4.980 & $3^{496672}$ \\
Advances in Health Sciences Education Theory & 1.852 & $1^{51}$ \\
and Practices & 17.135 & $1^{53}$ \\
Annals of Internal Medicine & 20.785 & $4^{31547178}$ \\
\hline British Medical Journal & 2.502 & $1^{55}$ \\
Medical Teacher & 6.784 & $2^{5862}$ \\
Canadian Medical Association Journal & 6.434 & $1^{73}$ \\
American Journal of Bioethics & 17.333 & $1^{76}$ \\
Archives of Internal Medicine & & $1^{79}$ \\
\hline
\end{tabular}

practices, role modelling, mentoring and professional clinical practice, and public roles and medical professionalism. While these topics highlight major issues related to medical professionals, topics related to transition of firstyear students from being laypersons to being members of the medical profession, how medical schools change assessment to focus much more on a student's attitudes and personal development as a professional, not just on his or her knowledge of medicine, as well as strategies to introduce new teaching/learning approaches that facilitate the integration of medical professionalism across the years in the medical curriculum and demonstration of professional behaviour in day-to-day practices may be lacking. ${ }^{80}$
The study revealed the characteristics of the 50 mostcited articles; the following points are worth discussion:

First, the study demonstrated that there is no significant correlation between the citation counts and the number of authors or the number of female authors. The number of authors and females in authorship varied from 1 to 19 and from 0 to 11 , respectively. The two questions that can be raised in this regard; are we expecting an increase in number of citations as the number of authors increases? And is the gender of authors a factor affecting citation counts? Several studies indicated that a number of authors or the gender of authors are not among the factors affecting the citation received by a publication;

Table 4 Authors and coauthors of two or more articles

\begin{tabular}{|c|c|c|c|c|c|}
\hline \multirow[b]{2}{*}{ Author's name } & \multicolumn{2}{|c|}{ No (reference) } & \multirow[b]{2}{*}{ Author's name } & \multicolumn{2}{|c|}{ No (reference) } \\
\hline & First author & Coauthor & & First author & Coauthor \\
\hline Epstein & $2^{3032}$ & - & Greysen & $1^{69}$ & $1^{39}$ \\
\hline Kimball & - & $2^{3133}$ & Mann & - & $2^{4077}$ \\
\hline Brennan & $1^{33}$ & $1^{64}$ & Dyrbye & $1^{41}$ & $1^{48}$ \\
\hline Blumenthal & - & $2^{3354}$ & Sloan & - & $2^{4148}$ \\
\hline Papadakis & $4^{34377174}$ & - & Shanafelt & - & $2^{4148}$ \\
\hline Teherani & - & $2^{3437}$ & Holmboe & - & $2^{7177}$ \\
\hline Veloski & $1^{56}$ & $1^{34}$ & Coulehan & $2^{4647}$ & - \\
\hline Hodgson & - & $2^{3437}$ & Cruess and Cruss & $2^{5058}$ & $1^{66}$ \\
\hline Levinson & - & $2^{5275}$ & & & \\
\hline Gruen & $1^{64}$ & $1^{54}$ & & & \\
\hline
\end{tabular}


Table 5 Assessing the impact of publication variables on citation scores and altmetric scores using multivariate analysis

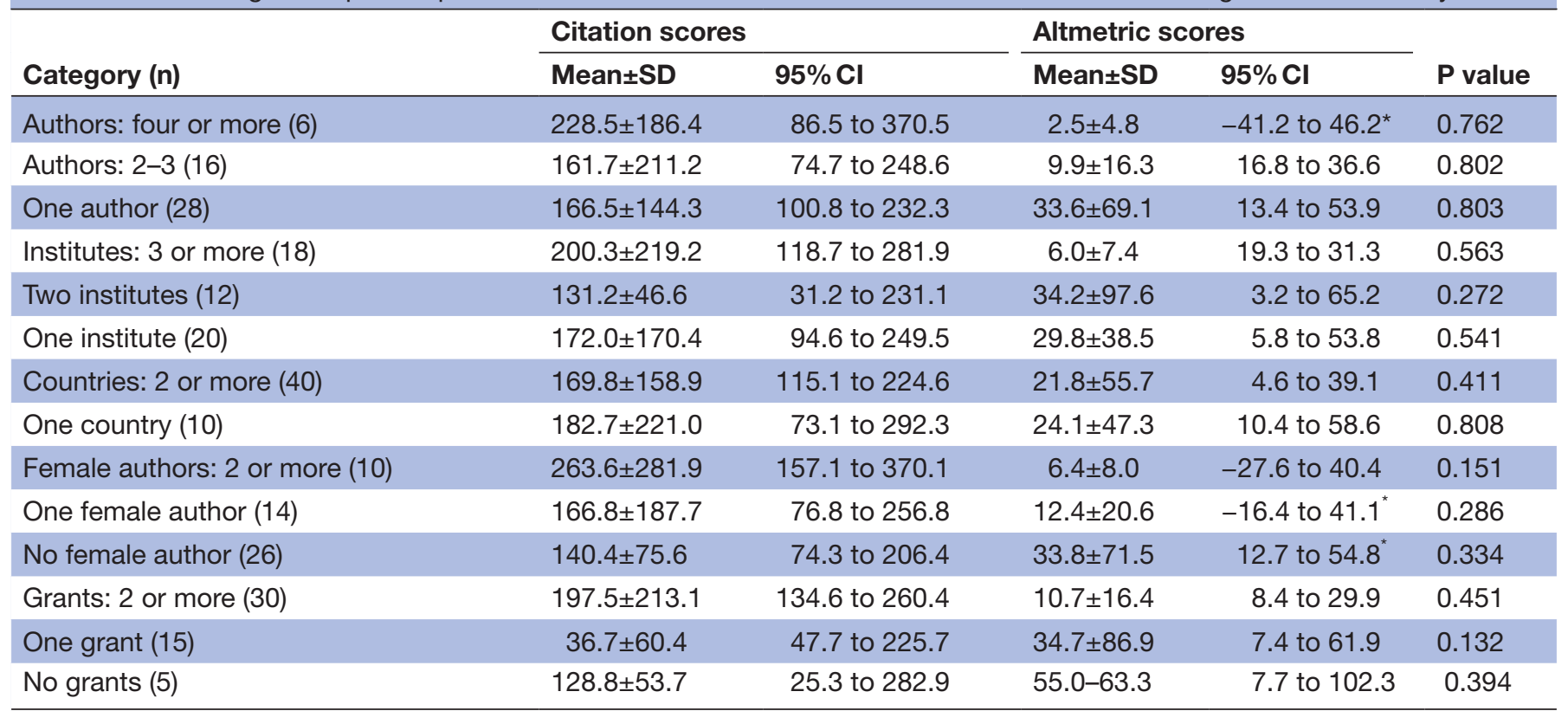

None of the categories studied caused significant differences on the citation scores or the altmetric scores.

*The analysis involved subgroups, smaller sample size, and because the smaller altmetric scores for these subgroups, the $\mathrm{Cl}$ was negative.

factors such as having a higher level of evidence may be more likely to affect citation counts. ${ }^{81}$

Although the proportion of women in authorship of original research in the USA in general has significantly increased in the last four decades and more women are enrolling Master's and PhD degrees, ${ }^{82}$ women still compose a minority of the authors of original research and there are some differences by subfield. ${ }^{83} 84$ Recently, an increased satisfaction about the proportion of women faculty, especially full professors in academic medicine, has been reported, suggesting an improvement in the balance at least in this subfield. ${ }^{85}$

Second, the study showed significant correlation between the citation counts and the number of countries involved, but not the number of institutes. However, further analysis using multivariate analysis model did not show significant relationships at different subgroups. While Figg et $a l^{86}$ reported that there is a correlation between the number of authors and the number of times an article is cited by other researchers, the work of GarcíaAroca $e$ t $a l^{87}$ showed that publishing in English in certain journals and collaborating with certain authors and institutes increase the visibility of the manuscripts published on the subject. Therefore, it is the quality of collaboration rather than the absolute number of these parameters. Recently, Tanner-Smith and Polanin showed that studies conducted by more established authors (have higher h-indices) and reported in more prestigious journal outlets are more likely to be cited by other scholars, even after controlling for various proxies of study quality. ${ }^{88}$

Third, the study showed no significant correlation between the number of citations and the number of grants received. This finding is not surprising. Recently, it was shown that too many of the US authors of most influential papers in science do not receive National Health (NH) funding. ${ }^{89}$ Another group of researchers found no association between grant percentile ranking and grant outcome as assessed by number of top- $10 \%$ articles per dollar million spent. ${ }^{90}$ Interestingly, the work of Gök et $a \ell^{11}$ showed that funding on its own is not a measure of citation impact but is principally related to funding variety and negatively related with funding intensity. Also, there was an inverse relationship between the relative frequency of funding and citation impact.

Fourth, the lack of significant correlation between the number of citations and the number of years since publication may indicate that the higher citations are not due to ageing of articles but possibly due to the new knowledge discussed and the evidence presented by authors to answer challenging questions. In fact, the majority of these articles $(36,72 \%)$ were published in 2003-2011 and the oldest article in the list was published in 1994.

The USA, Canada and the UK contributed most to these articles. The leadership of universities from these countries in medical professionalism is no surprise. Altmetrics have a number of functions including: first, a record of the degree to which people, public and academics/ clinicians, engaged with a scholarly publication. Second, a measure of the dissemination of a scholarly work including the geographical and demographic details of those involved in such discussions on social media channels. Third, possibly an indirect measure of influence and impact of scholarly work.

The idea of 'altmetrics' or social web metrics was first proposed by Priem and Hemminger ${ }^{92}$ and is based on the hypothesis that the analysis of scientific outputs and 
discussions in social media tools can be used as an alternative to citation bibliometrics created by Garfield. ${ }^{93}$ The hypothesis may bring new insight into the understanding of scientific impact and the type of relationship between alternative metrics and citation scores. However, currently, there is evidence that the use of social media in promoting and discussing research is low in the research community. It has been reported that $15 \%-25 \%$ of scientific publications have some altmetric activities and these activities are observed mostly in recent publications in social sciences, humanities, medical and life sciences. ${ }^{94}$ With these limitations in mind, it is clear that altmetrics open new directions in understanding scientific impact of a publication not just through peer-review and citation indices, but through assessing other aspects of impact at society, education and public domains. While Powell et al found a correlation between number of citations and altmetric scores for articles published after 2000, ${ }^{95}$ we found significant correlation for articles published in 2007 and after. No correlation was found for articles published in 2006 or earlier. Our findings and those of Powell et al indicate the presence of such correlation for articles published after the year 2000 .

This study has several strengths, firstly: the search was conducted by two researchers independently using four approaches with the aim to maximise the outcomes of the search and not to miss a publication. Second: the study examined the citation numbers, related bibliometric parameters and altmetric scores, the relationships between these variables and their possible effect on citation counts and altmetric scores were evaluated using correlation studies and multivariate analysis. Third: the study covered top-cited articles on medical professionalism over the last two decades. However, this study is not without limitations, First, we limited the search to Web of Science database, and we have not searched other databases such as Google Scholar or Scopus for reasons mentioned under methods. Also, we have searched highly cited journals in the area of medical education, ethics, bioethics, general medicine and surgery to compensate for using one database; and second, we limited the study to articles published in the English language. However, further evaluation revealed that articles published in languages other than English were not qualified for inclusion and their citation counts were below the article listed number 50 .

\section{CONCLUSIONS}

Using a multivariate analysis model and correlation studies showed that several bibliometric factors neither correlated with citation scores nor altmetric scores. These variables included, years since publication, the number of authors, the number of female authors, the number of institutes and the number of grants received. The number of females in authorship (40\% of total number of authors) highlights the progressive role of females in medical education and the area of medical professionalism. It may be premature to make conclusive remarks about the significance of altmetric scores. However, the finding of correlations between the number of citations and altmetric scores of articles published in 2007 and after provides an additional parameter to the value of altmetric scores.

Acknowledgements Authors wish to thank Diana Sanad for her assistance in reviewing the manuscript.

Contributors SAA conceived and designed the study; collected and performed the search of databases, analysis and interpretation of findings, and drafting the manuscript. SA shared in the search of databases, analysis of findings and critical revision of the manuscript. Both authors approved the manuscript for publication.

Funding This work was funded by the College of Medicine Research Center, Deanship of Scientific Research, King Saud University, Riyadh, Saudi Arabia.

Competing interests None declared.

Patient consent for publication Not required.

Provenance and peer review Not commissioned; externally peer reviewed.

Data sharing statement All data relevant to the study are included in the article or uploaded as online supplementary information.

Open access This is an open access article distributed in accordance with the Creative Commons Attribution Non Commercial (CC BY-NC 4.0) license, which permits others to distribute, remix, adapt, build upon this work non-commercially, and license their derivative works on different terms, provided the original work is properly cited, appropriate credit is given, any changes made indicated, and the use is non-commercial. See: http://creativecommons.org/licenses/by-nc/4.0/.

\section{REFERENCES}

1. Danthi N, Wu CO, Shi P, et al. Percentile ranking and citation impact of a large cohort of National Heart, Lung, and Blood Institute-funded cardiovascular R01 grants. Circ Res 2014;114:600-6.

2. Costello LC. Perspective: is NIH funding the "best science by the best scientists"? A critique of the NIH R01 research grant review policies. Acad Med 2010;85:775-9.

3. Gast KM, Kuzon WM, Waljee JF. Bibliometric indices and academic promotion within plastic surgery. Plast Reconstr Surg 2014;134:838e-44.

4. Klosik DF, Bornholdt S. The citation wake of publications detects nobel laureates' papers. PLoS One 2014;9:e113184.

5. Choi M, Holliday EB, Jagsi R, et al. Citation-based Estimation of Scholarly Activity Among Domestic Academic Radiation Oncologists: Five-Year Update. J Radiat Oncol 2014;3:115-22.

6. Susarla HK, Dhar V, Karimbux NY, et al. Do Standard bibliometric measures correlate with academic rank of full-time pediatric dentistry faculty members? J Dent Educ 2017;81:427-32.

7. Aoun SG, Bendok BR, Rahme RJ, et al. Standardizing the evaluation of scientific and academic performance in neurosurgery-critical review of the " $\mathrm{h}$ " index and its variants. World Neurosurg 2013;80:e85-e90.

8. Moustafa K. Aberration of the Citation. Account Res 2016;23:230-44.

9. Perneger TV. Online accesses to medical research articles on publication predicted citations up to 15 years later. $J$ Clin Epidemiol 2015;68:1440-5.

10. Duyx B, Urlings MJE, Swaen GMH, et al. Scientific citations favor positive results: a systematic review and meta-analysis. J Clin Epidemiol 2017;88:92-101.

11. Bornmann L, Daniel Hans-Dieter. What do citation counts measure? A review of studies on citing behavior. Journal of Documentation 2008;64:45-80.

12. Kolahi J, Iranmanesh P, Khazaei S, et al. Altmetric analysis of 2015 dental literature: a cross sectional survey. Br Dent J 2017;222:695-9.

13. Kirk LM. Professionalism in medicine: definitions and considerations for teaching. Proc 2007;20:13-16.

14. Azer SA. Exploring the Top-Cited and Most Influential Articles in Medical Education. J Contin Educ Health Prof 2016;36(Suppl 1):S32-S41.

15. Azer SA. The top-cited articles in medical education: a bibliometric analysis. Acad Med 2015;90:1147-61.

16. Azer SA. Top-Cited Articles in Problem-Based Learning: A Bibliometric Analysis and Quality of Evidence Assessment. J Dent Educ 2017;81:458-78. 
17. Azer SA, Azer S. Bibliometric analysis of the top-cited gastroenterology and hepatology articles. BMJ Open 2016;6:e009889.

18. Exploring the ACGME Core Competencies: Professionalism (Part 7 of 7). https://knowledgeplus.nejm.org/blog/acgme-core-competenciesprofessionalism/ (Accessed 30 Nov 2017).

19. ABIM Foundation. American Board of Internal MedicineACP-ASIM Foundation. American College of Physicians-American Society of Internal MedicineEuropean Federation of Internal Medicine. Medical professionalism in the new millennium: a physician charter. Ann Intern Med 2002;136:243-6.

20. O'Sullivan $\mathrm{H}$, van Mook W, Fewtrell $\mathrm{R}$, et al. Integrating professionalism into the curriculum: AMEE Guide No. 61. Med Teach 2012;34:e64-e77.

21. Birden H, Glass N, Wilson I, et al. Defining professionalism in medical education: a systematic review. Med Teach 2014;36:47-61.

22. Hafferty FW. Definitions of professionalism: a search for meaning and identity. Clin Orthop Relat Res 2006;449:193-204.

23. Van De Camp K, Vernooij-Dassen MJ, Grol RP, et al. How to conceptualize professionalism: a qualitative study. Med Teach 2004;26:696-702.

24. Tas F. Majority of the most-cited articles on cutaneous malignant melanoma are published in non-dermatology/melanoma specialized journals. J Cancer Res Ther 2016;12:612-5.

25. Altmetric support. What outputs and sources does altmetric track? https://help.altmetric.com/support/solutions/articles/6000060968what-outputs-and-sources-does-altmetric-track- (Accessed $30 \mathrm{Nov}$ 2017)

26. Altmetric support. How is the altmetric attention score calculated? https://help.altmetric.com/support/solutions/articles/6000060969how-is-the-altmetric-attention-score-calculated- (Accessed $30 \mathrm{Nov}$ 2017)

27. Altmetric support. Altmetri bookmarklet for researchers. https://www. altmetric.com/products/free-tools/bookmarklet/ (Accessed 30 Nov 2017).

28. Altmetric. The donut and altmetric attention score. https://www. altmetric.com/about-our-data/the-donut-and-score/ (Accessed 30 Nov 2017).

29. Nelson KP, Edwards D. Measures of agreement between many raters for ordinal classifications. Stat Med 2015;34:3116-32.

30. Epstein RM, Hundert EM. Defining and assessing professional competence. JAMA 2002;287:226-35.

31. Blank L, Kimball H, McDonald W, et al. Medical professionalism in the new millennium: a physician charter 15 months later. Ann Intern Med 2003;138:839-41.

32. Epstein RM. Mindful practice. JAMA 1999;282:833-9.

33. Brennan TA, Rothman DJ, Blank L, et al. Health industry practices that create conflicts of interest: a policy proposal for academic medical centers. JAMA 2006;295:429-33.

34. Papadakis MA, Teherani A, Banach MA, et al. Disciplinary action by medical boards and prior behavior in medical school. N Engl J Med 2005;353:2673-82.

35. Swick HM. Toward a normative definition of medical professionalism Acad Med 2000;75:612-6.

36. Arnold L. Assessing professional behavior: yesterday, today, and tomorrow. Acad Med 2002;77:502-15.

37. Papadakis MA, Hodgson CS, Teherani A, et al. Unprofessional behavior in medical school is associated with subsequent disciplinary action by a state medical board. Acad Med 2004;79:244-9.

38. Neumann M, Edelhäuser F, Tauschel D, et al. Empathy decline and its reasons: a systematic review of studies with medical students and residents. Acad Med 2011;86:996-1009.

39. Chretien KC, Greysen SR, Chretien JP, et al. Online posting of unprofessional content by medical students. JAMA 2009;302:1309-15.

40. Kenny NP, Mann KV, MacLeod H. Role modeling in physicians' professional formation: reconsidering an essential but untapped educational strategy. Acad Med 2003;78:1203-10.

41. Dyrbye LN, Massie FS, Eacker A, et al. Relationship between burnout and professional conduct and attitudes among US medical students. JAMA 2010;304:1173-80.

42. Swick HM, Szenas P, Danoff D, et al. Teaching professionalism in undergraduate medical education. JAMA 1999;282:830-2.

43. Thompson LA, Dawson $\mathrm{K}$, Ferdig $\mathrm{R}$, et al. The intersection of online social networking with medical professionalism. J Gen Intern Med 2008;23:954-7.

44. Wynia MK, Latham SR, Kao AC, et al. Medical professionalism in society. N Engl J Med 1999;341:1612-6.

45. Newton BW, Barber L, Clardy J, et al. Is there hardening of the heart during medical school? Acad Med 2008;83:244-9.
46. Coulehan J, Williams PC. Vanquishing virtue: the impact of medical education. Acad Med 2001;76:598-605.

47. Coulehan J. Viewpoint: today's professionalism: engaging the mind but not the heart. Acad Med 2005;80:892-8.

48. Thomas MR, Dyrbye LN, Huntington JL, et al. How do distress and well-being relate to medical student empathy? A multicenter study. $J$ Gen Intern Med 2007:22:177-83.

49. Hilton SR, Slotnick HB. Proto-professionalism: how professionalisation occurs across the continuum of medical education. Med Educ 2005;39:58-65.

50. Cruess RL, Cruess SR. Teaching medicine as a profession in the service of healing. Acad Med 1997;72:941-52.

51. Audet AM, Doty MM, Shamasdin J, et al. Measure, learn, and improve: physicians' involvement in quality improvement. Health Aff 2005;24:843-53.

52. Wong BM, Etchells EE, Kuper A, et al. Teaching quality improvement and patient safety to trainees: a systematic review. Acad Med 2010;85:1425-39.

53. Eva KW, Cunnington JP, Reiter HI, et al. How can I know what I don't know? Poor self assessment in a well-defined domain. Adv Health Sci Educ Theory Pract 2004;9:211-24.

54. Campbell EG, Regan S, Gruen RL, et al. Professionalism in medicine: results of a national survey of physicians. Ann Intern Med 2007;147:795-802.

55. Littlewood S, Ypinazar V, Margolis SA, et al. Early practical experience and the social responsiveness of clinical education: systematic review. BMJ 2005;331:387-91.

56. Veloski JJ, Fields SK, Boex JR, et al. Measuring professionalism: a review of studies with instruments reported in the literature between 1982 and 2002. Acad Med 2005;80:366-70.

57. Rothman DJ. Medical professionalism--focusing on the real issues. $N$ Engl J Med 2000;342:1284-6.

58. Cruess RL, Cruess SR. Teaching professionalism: general principles. Med Teach 2006;28:205-8.

59. Kassebaum DG, Cutler ER. On the culture of student abuse in medical school. Acad Med 1998;73:1149-58.

60. Wear D, Castellani B. The development of professionalism: curriculum matters. Acad Med 2000;75:602-11.

61. Suchman AL, Williamson PR, Litzelman DK, et al. Toward an informal curriculum that teaches professionalism. Transforming the social environment of a medical school. J Gen Intern Med 2004:19:501-4.

62. Lynch DC, Surdyk PM, Eiser AR. Assessing professionalism: a review of the literature. Med Teach 2004;26:366-73.

63. Karnieli-Miller O, Vu TR, Holtman MC, et al. Medical students professionalism narratives: a window on the informal and hidden curriculum. Acad Med 2010;85:124-33.

64. Gruen RL, Pearson SD, Brennan TA. Physician-citizens--public roles and professional obligations. JAMA 2004;291:94-8.

65. Brainard $\mathrm{AH}$, Brislen $\mathrm{HC}$. Viewpoint: learning professionalism: a view from the trenches. Acad Med 2007;82:1010-4.

66. Steinert Y, Cruess S, Cruess R, et al. Faculty development for teaching and evaluating professionalism: from programme design to curriculum change. Med Educ 2005;39:127-36

67. Meisel A, Snyder L, Quill T. American College of Physicians-American Society of Internal Medicine End-of-Life Care Consensus Panel. Seven legal barriers to end-of-life care: myths, realities, and grains of truth. JAMA 2000;284:2495-501.

68. Hickson GB, Pichert JW, Webb LE, et al. A complementary approach to promoting professionalism: identifying, measuring, and addressing unprofessional behaviors. Acad Med 2007;82:1040-8.

69. Greysen SR, Kind T, Chretien KC. Online professionalism and the mirror of social media. J Gen Intern Med 2010;25:1227-9.

70. Eckles RE, Meslin EM, Gaffney M, et al. Medical ethics education: where are we? Where should we be going? A review. Acad Med 2005;80:1143-52.

71. Papadakis MA, Arnold GK, Blank LL, et al. Performance during internal medicine residency training and subsequent disciplinary action by state licensing boards. Ann Intern Med 2008;148:869-76.

72. MacDonald J, Sohn S, Ellis P, et al. Privacy, professionalism and Facebook: a dilemma for young doctors. Med Educ 2010;44:805-13.

73. Patenaude J, Niyonsenga T, Fafard D. Changes in students' moral development during medical school: a cohort study. CMAJ 2003;168:840-4

74. Papadakis MA, Osborn EH, Cooke M, et al. A strategy for the detection and evaluation of unprofessional behavior in medical students. University of California, San Francisco School of Medicine Clinical Clerkships Operation Committee. Acad Med 1999;74:980-90

75. Lesser CS, Lucey CR, Egener B, et al. A behavioral and systems view of professionalism. JAMA 2010;304:2732-7. 
76. Wear D, Kuczewski MG. The professionalism movement: can we pause? Am J Bioeth 2004:4:1-10.

77. Sargeant J, Armson H, Chesluk B, et al. The processes and dimensions of informed self-assessment: a conceptual model. Acad Med 2010;85:1212-20.

78. Reynolds PP. Reaffirming professionalism through the education community. Ann Intern Med 1994;120:609-14.

79. Aguilar I, Berger ZD, Casher D, et al. The "top 5" lists in primary care: meeting the responsibility of professionalism. Arch Intern Med 2011:171:13851390.

80. Azer SA, Al-Nassar S. Helping new students become medical professionals: what medical schools can do. Acad Med 2011;86:408

81. Cheng KL, Dodson TB, Egbert MA, et al. Which factors affect citation rates in the oral and maxillofacial surgery literature? J Oral Maxillofac Surg 2017:75:1313-8.

82. Gonzales LM, Allum JR, Sowell RS. Graduate enrollment and degrees: 2002 to 2012 (survey report). Washington DC: Council of Graduate Schools, 2013.

83. Jagsi R, Guancial EA, Worobey CC, et al. The "gender gap" in authorship of academic medical literature--a 35-year perspective. $N$ Engl J Med 2006;355:281-7.

84. Piper CL, Scheel JR, Lee Cl, et al. Gender Trends in Radiology Authorship: A 35-Year Analysis. AJR Am J Roentgenol 2016;206:3-7.

85. Valantine HA, Grewal D, Ku MC, et al. The gender gap in academic medicine: comparing results from a multifaceted intervention for stanford faculty to peer and national cohorts. Acad Med 2014;89:904-11.

86. Figg WD, Dunn L, Liewehr DJ, et al. Scientific collaboration results in higher citation rates of published articles. Pharmacotherapy 2006;26:759-67.
87. García-Aroca MÁ, Pandiella-Dominique A, Navarro-Suay R, et al. Analysis of Production, Impact, and Scientific Collaboration on Difficult Airway Through the Web of Science and Scopus (19812013). Anesth Analg 2017;124:1886-96.

88. Tanner-Smith EE, Polanin JR. Brief alcohol intervention trials conducted by higher prestige authors and published in higher impact factor journals are cited more frequently. J Clin Epidemiol 2016;75:119-25.

89. Nicholson JM, loannidis JP. Research grants: Conform and be funded. Nature 2012;492:34-6.

90. Lauer MS, Danthi NS, Kaltman J, et al. Predicting Productivity Returns on Investment: Thirty Years of Peer Review, Grant Funding, and Publication of Highly Cited Papers at the National Heart, Lung, and Blood Institute. Circ Res 2015;117:239-43.

91. Gök A, Rigby J, Shapira P. The impact of research funding on scientific outputs: Evidence from six smaller European countries. J Assoc Inf Sci Technol 2016;67:715-30.

92. Priem J, Hemminger BH. Scientometrics 2.0: Toward new metrics of scholarly impact on the social Web. First Monday. 2010. http:// firstmonday.org/htbin/cgiwrap/bin/ojs/index.php/fm/article/view/ 2874/2570

93. Garfield E. Citation indexing for studying science. Nature 1970;227:669-71.

94. Sud P, Thelwall M. Evaluating altmetrics. Scientometrics 2014;98:1131-43.

95. Powell A, Bevan V, Brown C, et al. Altmetric Versus Bibliometric Perspective Regarding Publication Impact and Force. World J Surg 2018;42:2745-56. 